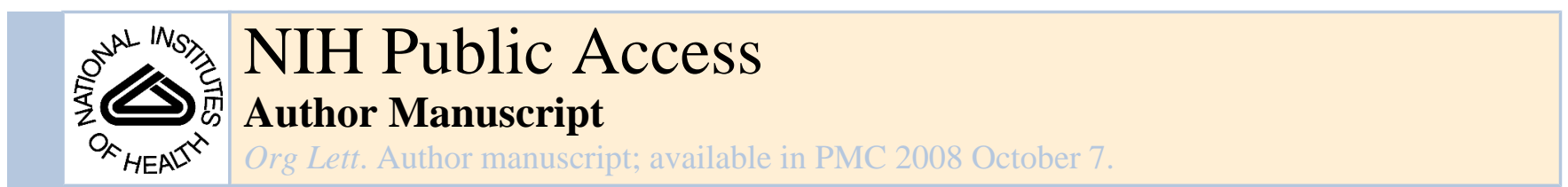

Published in final edited form as:

Org Lett. 2006 August 31; 8(18): 3983-3986. doi:10.1021/ol061438s.

\title{
Bridging Converts a Noncytotoxic nor-Paclitaxel Derivative to a Cytotoxic Analog by Constraining it to the T-Taxol Conformation
}

\author{
Shoubin Tang ${ }^{\dagger}$, Chao Yang ${ }^{\dagger}$, Peggy Brodie $^{\dagger}$, Susan Bane ${ }^{\ddagger}$, Rudravajhala Ravindra $^{\ddagger}$, \\ Shubhada Sharma $\ddagger$, Yi Jiang $\S$, James P. Snyder $\S$, and David G. I. Kingston ${ }^{\dagger}$ \\ $\dagger$ Department of Chemistry, M/C 0212, Virginia Polytechnic Institute and State University, Blacksburg, VA \\ 24061 \\ †epartment of Chemistry, State University of New York at Binghamton, Binghamton, NY 13902 \\ §Department of Chemistry, Emory University, Atlanta, GA 30322
}

\begin{abstract}
The synthesis of the bridged A-nor-paclitaxel 4 has been achieved from paclitaxel in a key test of the T-Taxol conformational hypothesis. Although the unbridged A-nor-paclitaxel 3 is essentially non-cytotoxic, the bridged analog 4 is strongly cytotoxic. This result provides strong evidence for the T-Taxol conformation as the bioactive tubulin-binding conformation of paclitaxel.
\end{abstract}

The natural product paclitaxel $(\mathrm{PTX})\left(\mathrm{Taxol}^{\mathrm{TM}}, \mathbf{1}\right)$ is a clinically approved drug for several tumor malignancies, ${ }^{1}$ and its chemistry and biology have been investigated extensively. ${ }^{2}$ It acts by promoting the polymerization of tubulin to stabilized microtubules, leading to apoptotic cell death, ${ }^{3-456}$ and its clinical activity is believed to be directly related to this microtubulebinding activity. ${ }^{6}$

Since the bioactivity of PTX is intimately connected with its tubulin-assembly properties, and since tubulin assembly is initiated by the non-covalent binding of paclitaxel to tubulin, the nature of this binding is a matter of great interest. In one scenario, a knowledge of the tubulinbinding conformation of paclitaxel would enable the design of simple non-taxoid compounds with comparable binding affinity and bioactivity.

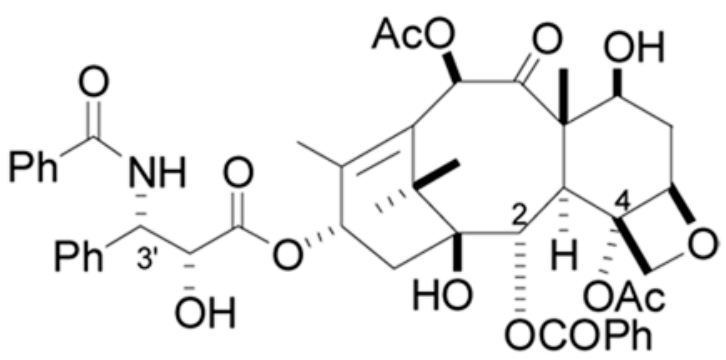

1

DKingston@vt.edu.

Supporting Information Available Detailed synthetic procedures for the synthesis of the bridged A-nor-paclitaxel 4 and A-nor-baccatin $\mathrm{III} 5,{ }^{1} \mathrm{H}$ and ${ }^{13} \mathrm{C}$ NMR spectra of compound $\mathbf{4}$, tubulin-GTP polymerization by compound $\mathbf{3}$, tubulin binding curves for $\mathbf{1}, \mathbf{3}$, and $\mathbf{4}$, and conformational searching, conformer extraction and binding site docking for $\mathbf{3}$ and $\mathbf{4}$. This material is available free of charge via the internet at http://pubs.acs.org. 
Although the taxane ring system of paclitaxel is relatively rigid, the compound has flexible side chains at $\mathrm{C} 2, \mathrm{C} 4, \mathrm{C} 10$, and notably at $\mathrm{C} 13$. As a result, there are many possible conformations available for binding to tubulin. Two different paclitaxel models of the tubulinbinding conformation were proposed based on NMR observables and molecular modeling. A "nonpolar" conformation was put forth on the basis of solution NMR investigations in nonpolar solvents, ${ }^{7-9}$ while similar studies in polar solvents were interpreted to favor a bound "polar" conformation. ${ }^{10}$ - Although most of the reports assumed a single conformation, deconvolution of PTX in $\mathrm{CDCl}_{3}{ }^{14}$ and $\mathrm{D}_{2} \mathrm{O} /$ DMSO- $\mathrm{d}_{6}{ }^{15}$ makes it clear that the molecule adopts 9-10 conformations, no one of which achieves a population above $30 \%$.

A second approach focused on tubulin-bound paclitaxel in the solid state. Application of REDOR NMR provided $\mathrm{F}_{-}{ }^{13} \mathrm{C}$ distances of 9.8 and $10.3 \AA$ between the fluorine of a 2- $(p-$ fluorobenzoyl)PTX and the $\mathrm{C} 3^{\prime}$ amide carbonyl and $\mathrm{C} 3^{\prime}$ methine carbons, respectively. ${ }^{16} \mathrm{~A}$ related examination reported a distance of $6.5 \AA$ between the fluorines of 2-( $p$ -

fluorobenzoyl)-3'-( $p$-fluorophenyl)-10-acetyldocetaxel; and, like the first solid state study, proposed the polar form to be tubulin-bound. $17,18,19$

The "polar" and "nonpolar" conformations have inspired several elegant synthetic studies designed to generate constrained analogs which maintain these conformations, but none of these constrained analogs have shown tubulin-polymerization or cytotoxic activities equal to or greater than those of PTX itself. Various compounds designed to mimic the "polar" conformation were either inactive $\mathrm{e}^{20}$ or less active than PTX. 21 Analogs based on the "nonpolar" conformation were also less active than PTX. $22-25$

A more fruitful approach stems from the electron crystallographic (EC) structure of $\alpha \beta$-tubulin stabilized by $\mathrm{Zn}^{2+}$ and PTX. It provides a detailed view of subunit structure, but at $3.7 \AA$ resolution leaves the PTX conformation unresolved. ${ }^{26} \mathrm{~A}$ model derived from intersection of PTX NMR and X-ray conformations with the EC density led to the proposal of T-Taxol as the bound conformation. ${ }^{27}$ A concurrent $\mathrm{EC}$ refinement ${ }^{28}$ at 3.5 Å resolution provided additional confidence in the model. Following these developments, a T-like conformer with a reorganized $\mathrm{C}-13$ side chain (PTX-NY) was proposed as an alternative binding model. ${ }^{29,30}$ However, this conformer is inconsistent with the EC density. 31,32

We report here an indirect method to establish the nature of the tubulin-taxane binding conformation more firmly. As described in more detail elsewhere ${ }^{33}$ we previously designed and prepared several bridged analogs such as $\mathbf{2}$ based on the T-Taxol or butterfly conformation. The latter juxtaposes the $\mathrm{C} 3$ '-phenyl and C4-OAc groups and encouraged the construction of taxanes with bridges linking these positions. Three of the analogs have tubulin-assembly and cytotoxic activities superior to those of paclitaxel, providing strong support for the T-Taxol conformation. ${ }^{33,34}$ Nonetheless, the actual improvement in bioactivity is relatively modest, varying from a 22-fold increase in cytotoxicity in the A2780 bioassay to a factor of 1.4 in the case of the PC3 prostate cancer cell line. 33

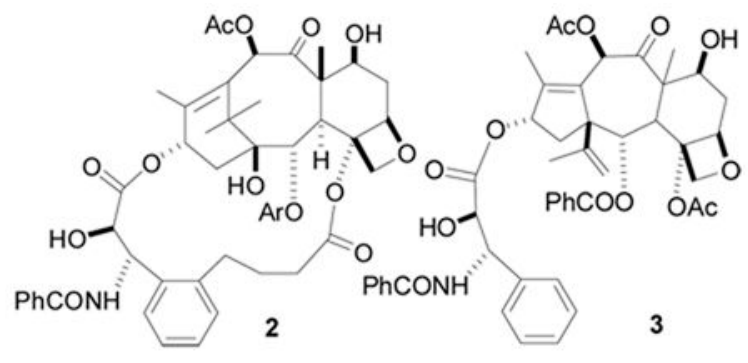

Org Lett. Author manuscript; available in PMC 2008 October 7. 
Tubulin-assembly activity appears to be less sensitive to structural variations than cytotoxicity, but 2 had an $\mathrm{ED}_{50}$ for tubulin polymerization of $0.21 \mu \mathrm{M}$ as compared with paclitaxel's 0.50 $\mu \mathrm{M} .{ }^{33}$ We thus elected to carry out a rigorous test of the T-Taxol hypothesis by determining the effect of bridging on the bioactivity of the much less active starting compound A-norpaclitaxel (3).

A-nor-paclitaxel, or (1 $\alpha)$-15(16)-anhydro-11(15 $\rightarrow 1)$-abeotaxol (3), is an A-ring contracted paclitaxel analog that was first reported by us in 1991.35 Biological studies revealed that 3 was much less cytotoxic than paclitaxel towards the KB cell line, but that it retained ability to inhibit tubulin disassembly at a level about one third that of paclitaxel. ${ }^{36}$ A preliminary molecular modeling study showed that the rearranged A-nor-baccatin core of A-nor-paclitaxel has a similar conformation to that the baccatin core of paclitaxel. As a result, a number of A-norpaclitaxel analogs with modifications on the $\mathrm{C}-1$ isopropenyl moiety and the $\mathrm{C}-2$ benzoyl group were prepared. A few of these analogs showed enhanced tubulin binding activities, in some cases to the same level as that of paclitaxel, but none possessed comparable cytotoxicity. 37 , 38 Interestingly, unlike PTX, where some modifications on the C-2 benzoyl group increase tubulin-assembly activity, the same modifications on the C-2 benzoyl group of A-norpaclitaxel uniformly decrease tubulin-assembly activity. ${ }^{38}$ Based on this information, the bridged compound $\mathbf{4}$ provides an excellent critical test of the T-Taxol hypothesis, since any cytotoxicity observed would represent a significant increase in bioactivity due to the imposed conformational lock.

We investigated two separate approaches to the synthesis of 4 . The first approach involved the synthesis of the A-nor-baccatin III 5 and subsequent attachment of a modified side chain and olefin metathesis to form the bridge. This approach was selected because of its flexibility, since it could in principle be adapted to prepare several compounds with different chain lengths.

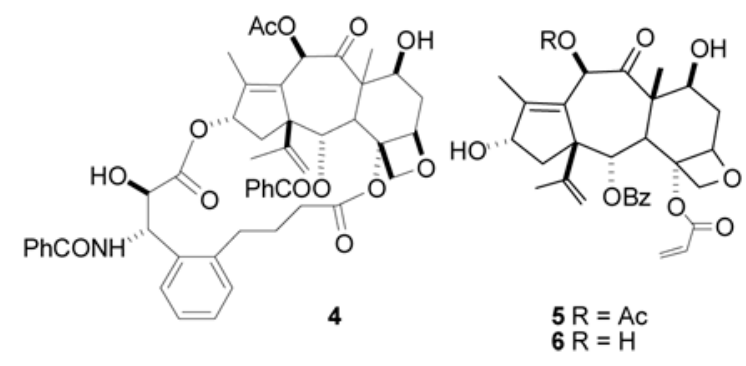

The approach failed, however, at the point of the conversion of the 10-deacetyl derivative 6 to 5. We thus elected to pursue the simpler direct route of conversion of a preformed bridged derivative to its A-nor analog.

The known compound dihydrobritaxel-5 was prepared as previously described ${ }^{33}$ and converted to the silyl protected compound 7. This was then treated with $\mathrm{SOCl}_{2}$ at $-20^{\circ} \mathrm{C}$ to give the A-nor derivative $\mathbf{8}$ (Scheme 1). The resulting compound was then deprotected to yield the desired product $\mathbf{4}$. The unbridged A-nor-paclitaxel $\mathbf{3}$ was also prepared as previously described ${ }^{35}$ for comparison purposes.

PTX and compounds 3 and $\mathbf{4}$ were evaluated for tubulin-assembly capacity, tubulin binding ability and cytotoxicity against the A2780 and PC 3 cell lines (Table 1). Impressively, the bridged A-nor-paclitaxel $\mathbf{4}$ binds to GMPcPP microtubules with slightly greater affinity than PTX itself and is more efficacious by a factor of 2 in lowering the critical concentration of tubulin-GDP. The enhanced tubulin polymerization activity $\left(\mathrm{ED}_{50}\right)$ of compound $\mathbf{4}$ is probably due to an increase in both the ligand's efficacy and its affinity for tubulin (Table 1). 
The unbridged A-nor-analog $\mathbf{3}$ was only weakly active in all of the assays performed. For example, no inhibition of fluorescent PTX binding to GMPcPP microtubules was observed at concentrations of $\mathbf{3}$ up to $40 \mu \mathrm{M}$ (curves shown in Supplementary Material). The association constant for the binding of $\mathbf{3}$ to microtubules was therefore estimated to be at least two orders of magnitude less that that of PTX. The more active tubulin-GTP rather than tubulin-GDP was required to measure critical concentration. The critical concentration of tubulin-GTP in the presence of 1:1 molar ratio of $\mathbf{3}$ was $>3 \mu \mathrm{M}$, which is at least eight times the value determined for PTX under these conditions $(0.37 \mu \mathrm{M}) .^{3}$

In cytotoxicity assays, the analog $\mathbf{4}$ shows significant cytotoxic activity to the A2780 and the PC 3 cell lines, although it is still less active than PTX; in the PC3 cell line it is threefold less cytotoxic than PTX (1). In contrast, the unbridged A-nor-paclitaxel 3 is essentially noncytotoxic, with $\mathrm{IC}_{50}$ values too weak to be determined.

These results indicate that a bridged A-nor-paclitaxel which can maintain a "T-taxol" conformation also retains all of paclitaxel's tubulin-assembly activity and much of its cytotoxicity. This work thus offers further evidence for the significance of the T-taxol conformation for tubulin binding and tubulin assembly.

In an attempt to understand the origin of the differences between A-nor PTX 3 and bridged Anor PTX 4, we performed extensive conformational searches for these structures and located 464 and 613 fully-optimized conformations, respectively. The latter were examined for the presence of the polar, nonpolar, PTX-NY and T-Taxol conformers. Bridged 4 delivered 61 Tform minima, while acyclic 3 yielded 75 such conformers. In each of the latter cases, one of the top two fits provides a very close match to the structure of T-Taxol (Figure 1). By comparison, neither the polar nor the PTX-NY types are present in the conformers of $\mathbf{4}$, although the acyclic set (3) contains them. In addition, the nonpolar form of $\mathbf{4}$ docks poorly into the binding site (See SI). Accordingly, we give the latter three rotamers no further consideration.

To compare the compounds in the taxoid binding site, both $\mathbf{3}$ and $\mathbf{4}$ were docked into $\beta$-tubulin with the Glide protocol using flexible ligand docking and the OPLS force field. Both were found to readily adopt the T-form (see SI). The MMFF/GBSA $\left(\mathrm{H}_{2} \mathrm{O}\right)$ energy differences between the docked structures and the respective conformational search global minima for the A-nor analogs were computed to show that the energy gap $(\Delta \Delta \mathrm{E})$ is $1.7 \mathrm{kcal} / \mathrm{mol}$ smaller for bridged 4 than acyclic 3. With the AMSOL/ SM5.4PDA/CM1 aqueous solvation model, ${ }^{39}$ we estimated that the free energies of solvation for the two docked structures favor the bridged Anor-taxol by $0.6 \mathrm{kcal} / \mathrm{mol}$, reducing $\Delta \Delta \mathrm{E}$ to $1.1 \mathrm{kcal} / \mathrm{mol}$.

To place the latter combination energy difference in the context of the biological data of Table 1, we note that bridged 4 is at least 23 and 600 fold more active than 3 in the A2780 and PC3 cytotoxicity assays, respectively (2000/89 and 8300/13.8). If we assume the $\mathrm{IC}_{50}$ 's can be roughly equated with the $\mathrm{Ki}$ 's, ${ }^{40}$ then $\Delta \Delta \mathrm{G}=-\mathrm{RT} \ln \left[\mathrm{K}_{\mathrm{i}}(\mathbf{4}) / \mathrm{K}_{\mathrm{i}}(\mathbf{3})\right]$ at $298 \mathrm{~K}$ is 1.8 and $3.8 \mathrm{kcal} /$ $\mathrm{mol}$, respectively. These numbers are in reasonable agreement with the calculated value of 1.1 $\mathrm{kcal} / \mathrm{mol}$. They suggest that the source of the activity of $\mathbf{4} \mathrm{vs} . \mathbf{3}$ resides in the relative strain energy associated with binding to tubulin in the T-Taxol conformation offset by a small desolvation penalty.

\section{Supplementary Material}

Refer to Web version on PubMed Central for supplementary material. 


\section{Acknowledgment}

This work was supported by the National Institutes of Health (Grant CA-69571) and we are grateful for this support. We thank William Bebout in the Department of Chemistry, Virginia Polytechnic Institute and State University, for mass spectroscopic determinations.

\section{References}

1. (a) Rowinsky EK. Ann. Rev. Med 1997;48:353-374. [PubMed: 9046968] (b) Crown J, O'Leary M. Lancet 2000;355:1176-1178. [PubMed: 10791395]

2. Kingston, DGI. Anticancer Agents from Natural Products. Cragg, GM.; Kingston, DGI.; Newman, DJ., editors. Boca Raton: CRC Press; 2005. p. 89-122. (b) Ojima I, Kuduk S, Chakravarty S. Adv. Med. Chem 1999;4:69-124.

3. Schiff PB, Fant J, Horwitz SB. Nature 1979;277:665-667. [PubMed: 423966]

4. Horwitz SB. Trends Pharmacol. Sci 1992;13:134-136. [PubMed: 1350385]

5. Jordan MA, Toso RJ, Thrower D, Wilson L. Proc. Natl. Acad. Sci. U.S.A 1993;90:9552-9556. [PubMed: 8105478]

6. Blagosklonny MV, Fojo T. Int. J. Cancer 1999;83:151-156. [PubMed: 10471519]

7. Dubois J, Guenard D, Gueritte-Voeglein F, Guedira N, Potier P, Gillet B, Betoeil J-C. Tetrahedron 1993;49:6533-6544.

8. Williams HJ, Scott AI, Dieden RA, Swindell CS, Chirlian LE, Francl MM, Heerding JM, Krauss NE. Can. J. Chem 1994;72:252-260.

9. Cachau RE, Gussio R, Beutler JA, Chmurny GN, Hilton BD, Muschik GM, Erickson JW. Supercomput Appl. High Perform. Comput 1994;8:24-34.

10. Vander Velde DG, Georg GI, Grunewald GL, Gunn CW, Mitscher LA. J. Am. Chem. Soc 1993;115:11650-11651.

11. Paloma LG, Guy RK, Wrasidlo W, Nicolaou KC. Chem. Biol 1994;1:107-112. [PubMed: 9383378]

12. Ojima I, Chakravarty S, Inoue T, Lin S, He L, Horwitz SB, Kuduk SC, Danishefsky SJ. Proc. Natl. Acad. Sci. U.S.A 1999;96:4256-4261. [PubMed: 10200249]

13. Ojima I, Kuduk SD, Chakravarty S, Ourevitch M, Begue J-P. J. Am. Chem. Soc 1997;119:5519_ 5527.

14. Snyder JP, Nevins N, Cicero DO, Jansen J. J. Am. Chem. Soc 2000;122:724-725.

15. Snyder JP, Nevins N, Jimenez-Barbero, Cicero D, Jansen JM. unpublished

16. Li Y, Poliks B, Cegelski L, Poliks M, Gryczynski Z, Piszczek G, Jagtap PG, Studelska DR, Kingston DGI, Schaefer J, Bane S. Biochemistry 2000;39:281-291. [PubMed: 10630987]

17. Ojima I, Inoue T, Chakravarty S. J. Fluorine Chem 1999;97:3-10.

18. The X-ray crystal structure of polar PTX (Ref. 19) utilized in Ref. 16 shows an F---F distance of 4.8 $\AA$ when the para-hydrogens of the phenyl rings at the $\mathrm{C}-2$ and $\mathrm{C}-3^{\prime}$ positions are replaced with fluorines $(\mathrm{r}(\mathrm{C}-\mathrm{F})=1.33 \AA$ )

19. Mastropaolo D, Camerman A, Luo Y, Brayer GD, Camerman N. Proc. Natl. Acad. Sci. U.S.A 1995;92:6920-6924. [PubMed: 7624344]

20. Boge TC, Wu Z-J, Himes RH, Vander Velde DG, Georg GI. Bioorg. Med. Chem. Lett 1999;9:30473052. [PubMed: 10571173]

21. Ojima I, Lin S, Inoue T, Miller ML, Borella CP, Geng X, Walsh JJ. J. Am. Chem. Soc 2000;122:53435353.

22. Ojima I, Geng X, Lin S, Pera P, Bernacki RJ. Bioorg. Med. Chem. Lett 2002;12:349-352. [PubMed: 11814794]

23. Geng X, Miller ML, Lin S, Ojima I. Org. Lett 2003;5:3733-3736. [PubMed: 14507217]

24. Querolle O, Dubois J, Thoret S, Dupont C, Guéritte F, Guénard D. Eur. J. Org. Chem 2003:542-550.

25. Querolle O, Dubois J, Thoret S, Roussi F, Montiel-Smith S, Guéritte F, Guénard D. J. Med. Chem 2003;46:3623-3630. [PubMed: 12904066]

26. Nogales E, Wolf SG, Downing KH. Nature 1998;391:199-203. [PubMed: 9428769]

Org Lett. Author manuscript; available in PMC 2008 October 7. 
27. Snyder JP, Nettles JH, Cornett B, Downing KH, Nogales E. Proc. Natl. Acad. Sci. U.S.A 2001;98:5312-5316. [PubMed: 11309480]

28. Lowe J, Li H, Downing KH, Nogales E. J. Mol. Biol 2001;313:1045-1057. [PubMed: 11700061]

29. Geney R, Sun L, Pera P, Bernacki RJ, Xia S, Horwitz SB, Simmerling CL, Ojima I. Chem.\& Biol 2005;12:339-348. [PubMed: 15797218]

30. The T-Taxol conformer proposed by Geney, Ojima and colleagues was named "REDOR-Taxol".(ref 29). However, since there are upwards of 100 PTX conformations that meet the REDOR constraints including T-Taxol (Ref 31, Ref 32), we refer to the Geney-Ojima model as New York paclitaxel (PTX-NY)

31. Johnson SA, Alcaraz A, Snyder JP. Org. Lett 2005;7:5549-5552. [PubMed: 16320988]

32. Alcaraz AA, Mehta AK, Johnson SA, Snyder JP. J. Med. Chem 2006;49:2478-2488. [PubMed: 16610791]

33. Ganesh T, Guza RC, Bane S, Ravindra R, Shanker N, Lakdawala AS, Snyder JP, Kingston DGI. Proc. Natl. Acad. Sci. U.S.A 2004;101:10006-10011. [PubMed: 15226503]

34. Metaferia BB, Hoch J, Glass TE, Bane SL, Chatterjee SK, Snyder JP, Lakdawala A, Cornett B, Kingston DGI. Org. Lett 2001;3:2461-2464. [PubMed: 11483035]

35. Samaranayake G, Magri NF, Jitrangsri C, Kingston DGI. J. Org. Chem 1991;56:5114-5119.

36. Yuan H, Kingston DGI, Long BH, Fairchild CA, Johnston KA. Tetrahedron 1999;55:9089-9100.

37. Chordia MD, Kingston DGI, Hamel E, Lin CM, Long BH, Fairchild CA, Johnston KA, Rose WC. Bioorg. Med. Chem 1997;5:941-947. [PubMed: 9208103]

38. Kingston DGI, Chaudhary AG, Chordia MD, Gharpure M, Gunatilaka AAL, Higgs PI, Rimoldi JM, Samala L, Jagtap PG, Giannakakou P, Jiang YQ, Lin CM, Hamel E, Long BH, Fairchild CR, Johnston KA. J. Med. Chem 1998;41:3715-3726. [PubMed: 9733497]

39. Hawkins GD, Cramer CJ, Truhlar DG. J. Phys. Chem 1996;100:19824-19839.

40. (a) Cheng Y-C, Prusoff WH. Biochem. Pharm 1973;22:3099-3108. [PubMed: 4202581] (b) Cheng HC. J. Pharm. Tox. Methods 2002;46:61-71. 

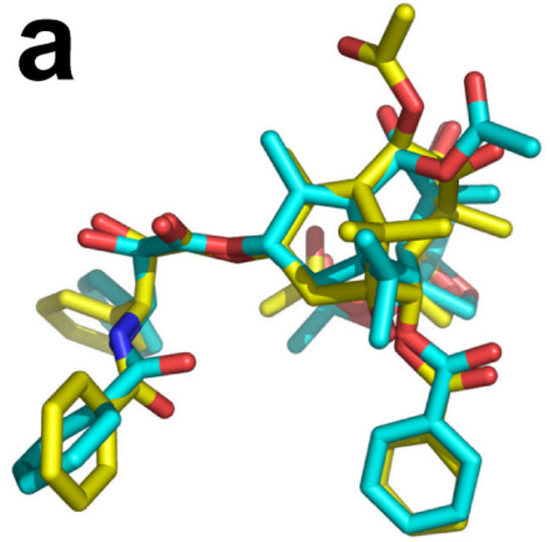

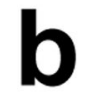

b

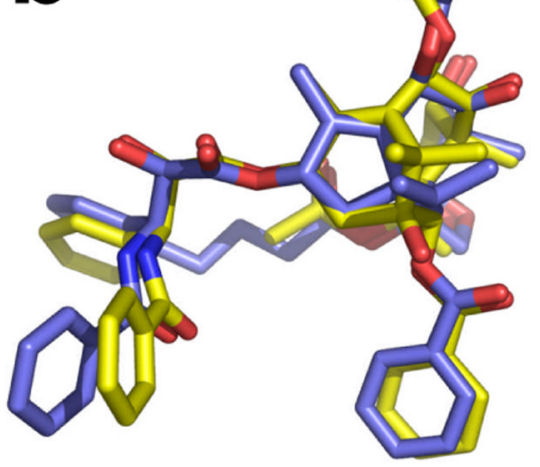

Figure 1.

Superposition of the centroids of the phenyl rings of fully-optimized T-forms of the A-nor PTX analogs and those of the corresponding rings of T-Taxol (yellow); a) acyclic $\mathbf{3}$ (cyan) (rms 0.35 $\AA$ ); b) bridged 4 (blue) (rms $0.31 \AA$ ). 


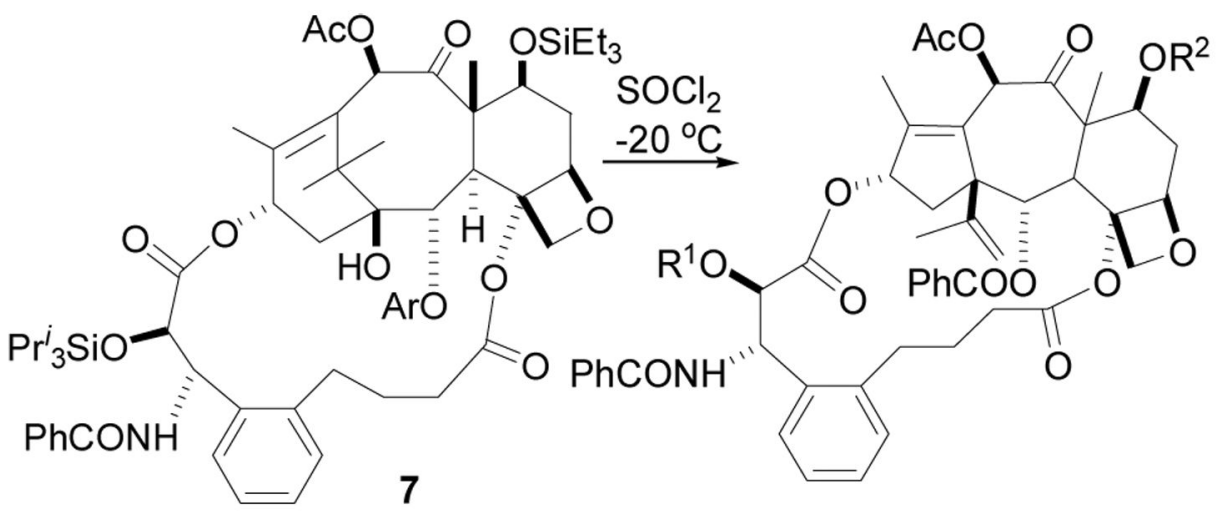

$$
H F / P y\left(\begin{array}{l}
8 R^{1}=\text { TIPS, } R^{2}=\text { TES } \\
4 R^{1}=R^{2}=H
\end{array}\right.
$$

Scheme 1.

Synthesis of $\mathbf{4}$ 


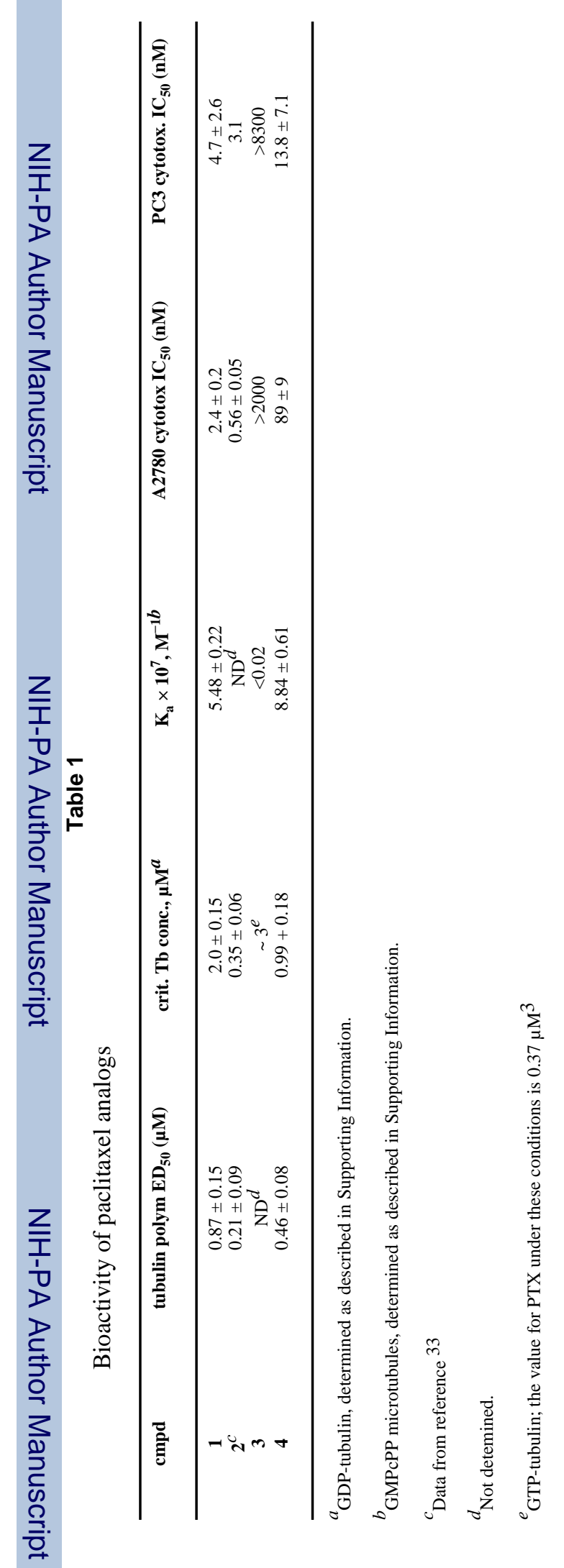

